\title{
Expression of D-type cyclins in mantle cell and diffuse large B-cell lymphomas
}

\author{
LENKA ZLAMALIKOVA ${ }^{1}$, MOJMIR MOULIS ${ }^{1}$, DAVID SALEK ${ }^{2}$, \\ JIRI JARKOVSKY ${ }^{3}$, JAN SMARDA ${ }^{4}$ and JANA SMARDOVA ${ }^{1,4}$ \\ Departments of ${ }^{1}$ Pathology and ${ }^{2}$ Hematooncology, University Hospital, 62500 Brno; \\ ${ }^{3}$ Institute of Biostatistics and Analyses, Faculty of Medicine, Masaryk University, 62500 Brno; \\ ${ }^{4}$ Department of Experimental Biology, Faculty of Science, Masaryk University, 61137 Brno, Czech Republic
}

Received November 11, 2015; Accepted December 7, 2015

DOI: $10.3892 /$ or.2016.4658

\begin{abstract}
D-type cyclins are involved in cell cycle regulation and play an important role in the pathogenesis of lymphomas. Aberrant expression of cyclin D1 is associated with mantle cell lymphoma (MCL) and serves as a diagnostic marker of MCL. Analysis of cyclin D expression in tumor tissues of patients with diffuse large B-cell lymphoma (DLBCL) which comprises a heterogeneous group of tumors may contribute to their stratification. We analyzed expression of cyclin D1, D2, and D3 mRNAs in $30 \mathrm{MCL}$ and 104 DLBCL patients using qRT-PCR and addressed their significance for disease outcome. We confirmed a high level of cyclin D1 mRNA in 29 MCL cases (97\%). One case (3\%) was identified as positive for cyclin D2. Expression of cyclin D1 was limited to MCL and did not occur in DLBCL. Overexpression of cyclin D2, which is rare in MCL, occurred more frequently in DLBCL (11 cases, 10.6\%). We showed that high expression of cyclin D2 in DLBCL cases de novo decreased the overall survival rate $(\mathrm{P}=0.016)$ and progression-free survival $(\mathrm{P}=0.009)$. The expression pattern of cyclin D3 was similar in both types of studied lymphomas and it did not affect the disease outcome.
\end{abstract}

\section{Introduction}

The D-type cyclins, cyclin D1, D2 and D3, are positive regulators of G1 phase progression. They form a complex with the cyclin-dependent kinase $\mathrm{Cdk} 4$ or $\mathrm{Cdk} 6$ to promote cell cycle entry. Overexpression of the D-type cyclins can shorten the G1 phase and reduce the cell's dependency on mitogens. This

Correspondence to: Professor Jana Smardova, Department of Pathology, University Hospital, Jihlavska 20, 62500 Brno, Czech Republic

E-mail: janasmarda@seznam.cz

Key words: mantle cell lymphoma, diffuse large B-cell lymphoma, D-type cyclins, qRT-PCR, immunoblotting function of D-type cyclins in cell cycle control provides them with potentially strong oncogenic power. Cyclins D1, D2 and D3 share both structural and functional similarities but they are expressed in a tissue-specific manner $(1,2)$.

Deregulation of cyclin D1 expression is a key pathogenic event in the development of mantle cell lymphoma (MCL). MCL is a relatively rare disease representing approximately 6-8\% of non-Hodgkin lymphomas (NHLs) and affecting predominantly males. The median overall survival is approximately 3-5 years. MCL is marked by chromosomal translocation $\mathrm{t}(11 ; 14)(\mathrm{q} 13 ; 32)$ leading to the juxtaposition of the $C C N D 1$ gene to the $I G H$ gene resulting in high expression of cyclin D1. In contrast, cyclin D1 is not typically expressed in normal lymphocytes $(3,4)$. Cyclin D1 overexpression is considered as a diagnostic marker of MCL. However, several cases of MCL with overexpression of cyclin D2 or D3 instead of cyclin D1 have been reported (5).

Diffuse large B-cell lymphoma (DLBCL) represents 30 to $40 \%$ of NHLs and comprises a heterogeneous group of tumors (6). In contrast to MCL, DLBCL cases are not associated with any specific genetic aberration. Instead, there are various genetic aberrations occurring with different frequencies that accompany this disease. They include rearrangements and mutations of BCL2, BCL6, $c-M Y C, C D K N 2 A$ and TP53 genes (7-11). Heterogeneity of the tumor is reflected in variable patient outcome. Gene expression profiling provides stratification to subgroups with different prognosis. In addition, individual biological markers with prognostic significance have been described (12-14).

DLBCLs are generally considered as cyclin D1-negative. However, some DLBCL cases expressing cyclin D1 without association with $\mathrm{t}(11 ; 14)$ have been recently reported. It seems though that they represent only a minority subgroup of DLBCLs (15-21). Expression of cyclin D2 has been also repeatedly studied in DLBCL. The fraction of cyclin D2-positive cases varies between 13 and $62 \%$ and this feature was shown to be an independent indicator of poor survival $(18,22-24)$. Cyclin D2 overexpression is closely associated with CD5-positive cases de novo (24). The CD5-positive cases de novo represent a DLBCL subtype predominantly occurring in females and characterized by a higher age at diagnosis and a significantly poorer survival compared to CD5-negative 
DLBCLs (25). The frequency of cyclin D3 overexpression in DLBCL cases ranges between 20 and $41 \%(18,24,26)$ and seems to be associated with poor response to chemotherapy and shorter overall survival (26).

We previously performed detailed analysis of cyclin D1 expression in a collection of 33 tumor samples of MCL cases (27). In this study, we present a widely extended study. We analyzed the expression of cyclin D1, D2 and D3 mRNAs in patients with MCL and DLBCL using qRT-PCR and investigated the impact on disease outcome. We showed that high expression of cyclin D2 tended to decrease the overall survival rate among DLBCL patients.

\section{Materials and methods}

Tissue samples. We studied a cohort of 30 patients diagnosed with MCL in the years 2007-2012 and 104 patients diagnosed with DLBCL in the years 2001-2013 at University Hospital Brno. All patients underwent surgical biopsy of the tumor tissue and were diagnosed by a pathologist according to the WHO classification. The fresh-frozen tissue samples as well as formalin-fixed, paraffin-embedded (FFPE) tumor tissue blocks were available for all patients. A cohort of MCL patients (M1-M30) consisted of 23 men and 7 women. Median age at diagnosis was 66.5 years. Three cytomorphological subtypes were recognized: common (20 cases), blastoid (6 cases) and a pleomorphic variant (3 cases). A cohort of DLBCL patients (B1-B104) consisting of 64 men and 40 women with median age 57.0 years exhibited centroblastic (45), immunoblastic (8), mediastinal (18), anaplastic (2) and other or unspecified morphological variants (10). Based on immunohistochemical staining, the DLBCL cases were subclassified into germinal center B-cell-like (GCB) [39/104 (37.5\%)] and non-GCB [65/104 (62.5\%) groups according to Hans et al (28) and into subgroups 1 [62/104 (59.6\%)] and 2 [42/104 (40.4\%)] according to Muris et al (29). Twenty-three patients developed DLBCL as a secondary tumor. DLBCL patients were treated with either standard R-CHOP therapy (61/81 de novo cases and 19/23 secondary cases) or intensive therapy (18/81 de novo cases and 4/23 secondary cases). Two patients with de novo disease underwent no therapy. All patients were informed consent and they signed written consent allowing inclusion into this study as approved by the Ethics Committee of the University of Brno. As a control, tissues from three healthy donors and the MOLP-8 and Jurkat cell lines were used.

Cell line. The MOLP-8 cell line expressing a high level of cyclin D1 (30) was kindly provided by Dr Eva Bartova, Institute of Biophysics, Academy of Sciences (Czech Republic). The Jurkat cell line expressing a high level of cyclin D3 (31) was kindly provided by Dr Ales Hampl, Faculty of Medicine, Masaryk University (Czech Republic). MOLP-8 and Jurkat cells were cultured in RPMI-1640 medium (L-glutamine, $\mathrm{NaHCO}_{3}$; Sigma-Aldrich, Prague, Czech Republic) supplemented with $20 \%$ fetal calf serum and $1 \%$ penicillin/streptomycin in $5 \%$ $\mathrm{CO}_{2}$ at $37^{\circ} \mathrm{C}$.

Immunohistochemistry. Endogenous peroxidase activity was blocked with 3\% hydrogen peroxide in methanol, for $10 \mathrm{~min}$. Antigen retrieval was performed in citrate buffer,
pH 6.0 (Dako, Glostrup, Denmark) at $121^{\circ} \mathrm{C}$ for $4 \mathrm{~min}$. The CD5-specific mouse monoclonal antibody (clone 4C7; Leica Biosystems, USA) diluted 1:50 was applied at $4^{\circ} \mathrm{C}$ overnight. The cyclin D1-specific rabbit monoclonal antibody (clone SP4; Zytovision, Germany) diluted 1:50 was applied at $4^{\circ} \mathrm{Covernight}$. Reactive sites were identified using biotinylated secondary antibody, peroxidase ABC (Vector Laboratories, USA), DAB (Dako), and counterstained with Mayer's haematoxylin.

Immunoblotting. Tissue samples were lysed in solution containing $150 \mathrm{mM} \mathrm{NaCl}, 50 \mathrm{mM} \mathrm{NaF}, 50 \mathrm{mM}$ Tris (pH 8.0), $5 \mathrm{mM}$ EDTA, $1 \% \mathrm{NP}-40$ and $1 \mathrm{mM}$ phenylmethylsulfonyl fluoride in ice for $30 \mathrm{~min}$, and the cell extract was centrifuged at $17,000 \mathrm{x} \mathrm{g}$ for $30 \mathrm{~min}$ to remove cell debris. The protein concentration was determined by the Bradford assay. Solubilized proteins were resolved by $10 \%$ SDS-PAGE and transferred onto a nitrocellulose membrane. Blots were blocked in $0.1 \%$ Tween-20 and 5\% low-fat milk in PBS for $1 \mathrm{~h}$ and probed with CD1.1 (Abcam, Cambridge, UK), Ab-4 (Thermo Fisher Scientific, Fremont, CA, USA), Ab-1 (Neomarkers, Fremont CA, USA) mouse monoclonal antibodies and actin rabbit monoclonal antibody (BD Biosciences, USA) at $4^{\circ} \mathrm{C}$. Blots were developed with the Dako peroxidase-conjugated secondary antibody (Dako) using the ECL chemiluminescence detection kit (GE Healthcare UK Limited, Little Chalfont, UK).

Real-time quantitative RT-PCR. The cyclin D1, D2 and D3 transcripts were quantitated by real-time reverse transcription PCR (qRT-PCR). Total RNA was extracted from the frozen tissue samples using the Nucleospin RNA kit (Macherey-Nagel, Hoerdt, France). RNA was reverse transcribed by ProtoScript II RT (New England BioLabs, Hitchin, UK) and cDNA was amplified and quantified using TaqMan ${ }^{\circledR}$ Universal PCR Master Mix (Applied Biosystems, Foster City, CA, USA) and TaqMan Gene Expression Assays for CCND1 (Hs00765553_m1), CCND2 (Hs00153380_m1), CCND3 (Hs00236949_m1) and GAPDH in a 7500 Real-Time PCR system (Applied Biosystems). Quantitative real-time PCR was performed using these conditions: an initial cycle at $95^{\circ} \mathrm{C}$ for $10 \mathrm{~min}$, followed by 50 bi-phasic cycles $95^{\circ} \mathrm{C} / 15 \mathrm{sec}$ and $60^{\circ} \mathrm{C} / 1 \mathrm{~min}$. Initial template concentration was calculated from the cycle number when the amount of PCR product passed a threshold set in the exponential phase of the PCR reaction. The threshold cycles $(\mathrm{Ct})$ were recorded for the target gene and reference gene $(G A P D H)$ in all samples. Relative gene expression was analyzed with the $2^{-\triangle \triangle \mathrm{CT}}$ method using the GAPDH gene as the endogenous control and negative control as a calibrator. Each PCR reaction was carried out in duplicates. At least two independent analyses were performed for each sample.

Statistical analyses. Standard descriptive statistics were applied in the analysis; absolute and relative frequencies for categorical variables and median supplemented with minimum-maximum range for continuous variables. The influence of monitored parameters on survival and progression-free survival was assessed by hazard ratio estimates from univariate Cox models. Graphic visualization of patient survival according to the monitored parameters was performed 

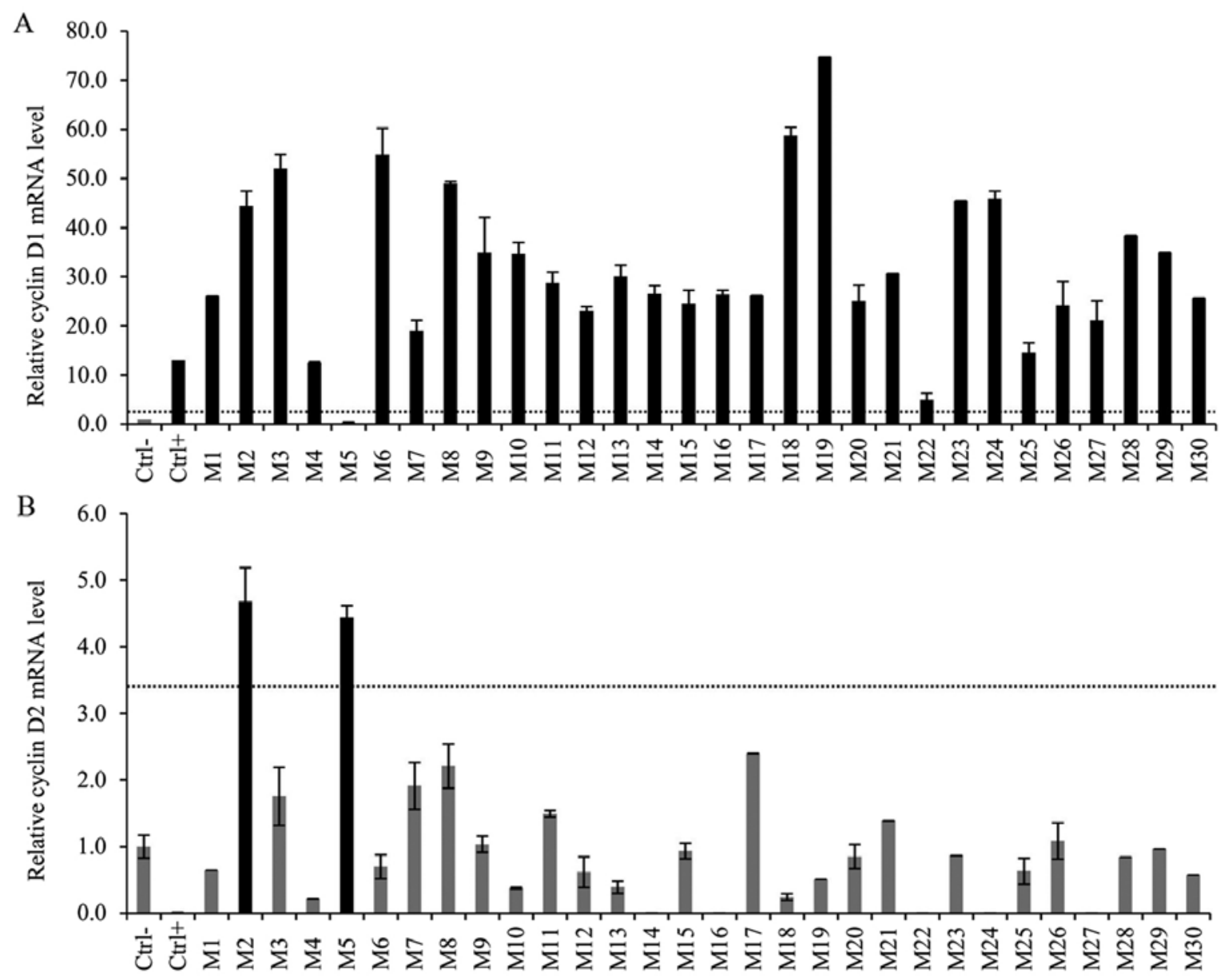

Figure 1. Analysis of the cyclin D mRNA level in the MCL samples by qRT-PCR. Relative quantification of cyclin D1 (A) and cyclin D2 (B) expression in comparison to healthy donors (Ctrl-) is presented. Data are expressed as means \pm SE. The myeloma MOLP- 8 cell line with high expression of cyclin D1 served as a positive control (Ctrl+).

using Kaplan-Meier survival curves. Statistical significance of differences in survival among groups of patients was tested using the log-rank test. $\alpha=0.05$ was used as a level of statistical significance. Analyses were performed in statistical software IBM SPSS Statistics 22.0.0.1 for Windows (IBM Corporation, 2014).

\section{Results}

Quantification of cyclin D1, D2 and D3 transcripts in $M C L$ and $D L B C L$. We used quantitative real-time PCR to analyze the level of cyclin D1, D2 and D3 mRNAs in all MCL and DLBCL samples, healthy specimens (negative controls) and the MOLP- 8 cells (positive control). As an internal standard, GAPDH mRNA was used. The ratio of $C C N D 1 / G A P D H$ (CCND2/GAPDH and $C C N D 3 / G A P D H$, respectively) in healthy specimens was designated as 1.0 and the normalized data of patient samples were calculated relative to this value. The cut-off level for altered cyclin D expression was set up as the mean value of $C C N D / G A P D H$ ratios determined in 3 samples from healthy donors plus 3 standard deviations (SD) and was determined as 2.8 for cyclin D1, 3.4 for cyclin D2, and 2.9 for cyclin D3. Values below these values were considered as negative. The MOLP- 8 control cells featuring high expres- sion of cyclin D1 and low expression of cyclin D2 and D3, reached a relative fold increase (RFI) of 13.0 for cyclin D1, 0.01 for cyclin D2 and 0.2 for cyclin D3 mRNAs.

The CCND1 mRNA expression of $7 \mathrm{MCL}$ cases was analyzed in our previous study (27). Twenty-three new MCL patients were enrolled. We confirmed overexpression of CCND1 mRNA in 29 out of 30 cases (97\%). The median relative fold increase was 27 (range 5.0-74.7). One case, M5, was previously reported as cyclin D1-negative (27 - case 25B) and analysis of the mRNA level confirmed this result (Fig. 1A). For all newly enrolled samples, the $\mathrm{t}(11 ; 14)$ translocation was assessed by FISH and competitive RT-PCR was performed as previously described (27), both with affirmative results: all new cases exhibited translocation $\mathrm{t}(11 ; 14)$ and expressed a high level of CCND1 mRNA (data not shown). Analysis of the CCND1 mRNA in 104 specimens from the DLBCL patients did not reveal any positivity. The relative fold increase of all samples was under the cut-off level reaching a median 0.3 (range 0.01-2.1). Fig. 2 illustrates the quantity of the CCNDI mRNA in the MCL and DLBCL cases.

The level of CCND2 mRNA scored above the cut-off level in 2 out of 30 MCL cases; in sample M5 which was earlier classified as cyclin D1-negative/cyclin D2-positive (27 - case 25B), and sample M2 with high expression of cyclin D1 (Fig. 1B). 


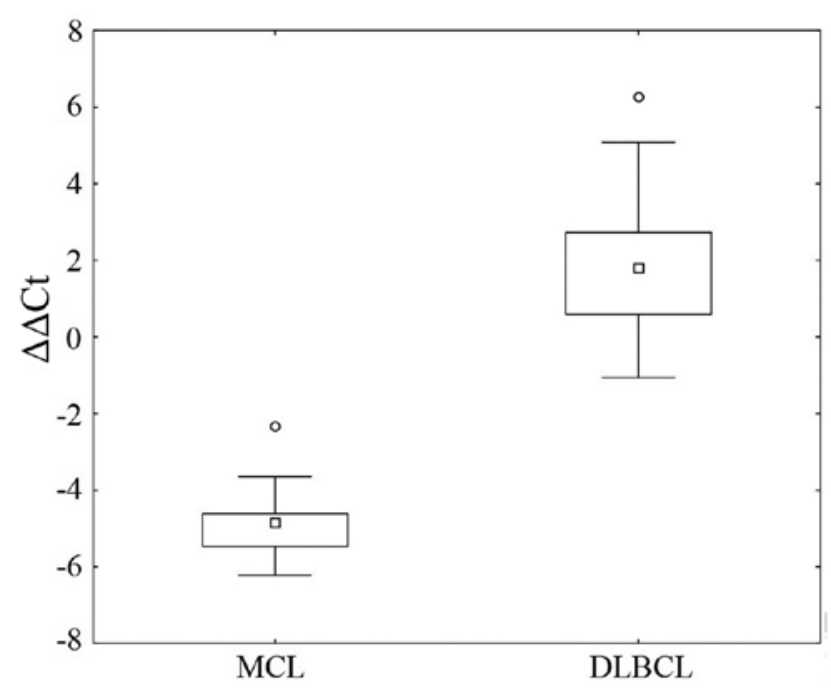

Figure 2. Statistical comparison of cyclin D1 mRNAs in the MCL and DLBCL samples. The box plot demonstrates the distribution of the $\Delta \Delta \mathrm{Ct}$ values measured by qRT-PCR. The greater the $\mathrm{Ct}$ value, the lower the cyclin D1 expression in the specimen.

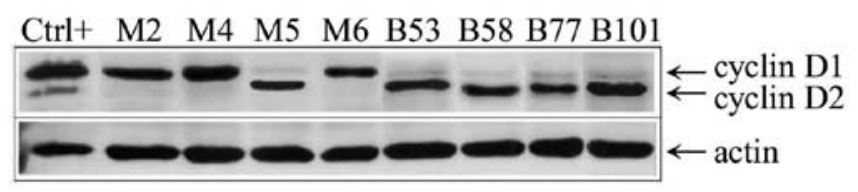

Figure 3. Protein analysis of cyclin D1 and D2 in representative MCL and DLBCL cases by immunoblotting. Monoclonal antibody CD1.1 was used. MOLP-8 cells served as a positive control (Ctrl+).

The level of the cyclin D2 protein in the samples was assessed by immunoblotting using the Ab-4 antibody and revealed a high level of cyclin D2 protein only in sample M5 (Fig. 3). In the DLBCL samples, the $C C N D 2$ mRNA was increased in 11 cases out of 104 (10.6\%) (Fig. 4A). The median relative fold increase reached 3.6 (range 3.4-5.7). Detection of the cyclin D2 protein in the DLBCL cases by immunoblotting confirmed the results (Fig. 3). Cyclin D2 positivity was not associated with any specific morphologic subtype. The majority of cyclin D2-positive cases were ranked in the centroblastic variant (4/45) reaching a frequency of $8.9 \%$. Among the immunoblastic cases, only one was cyclin D2-positive [1/8 (12.5\%)]. Similarly, expression of cyclin D2 was not associated with any immunohistochemically derived subgroup, neither GCB/non-GCB nor $1 / 2$. On the other hand, the cyclin D2 positivity was distinctively more frequent among secondary cases $[6 / 23(26.1 \%)]$ in comparison to cases de novo [5/81 (6.2\%)].

Finally, we quantified the CCND3 transcripts (Fig. 4B). Overexpression of $C C N D 3$ mRNA was found in 6 of the MCL cases (19.3\%) reaching a median of 3.3 (range 3.0-4.3). The M2 specimen exhibited high expression of all three cyclin D mRNAs. Concurrent overexpression of cyclin D2 and D3 mRNAs occurred in specimen M5. In the cohort of DLBCL cases, cyclin D3 mRNA overexpression occurred in 10 cases $(9.6 \%)$ reaching a median relative fold increase of 3.19 (range 3.1-5.8). Two specimens, B3 and B41, expressed cyclin D2 concurrently with cyclin D3 mRNA. The level of the cyclin D3 protein was assessed by immunoblotting using the Ab-1 antibody in the DLBCL samples confirming the results of qRT-PCR (Fig. 5).

Relationship between the expression of cyclin D in DLBCL and disease outcome. Next, we investigated the relationship between the expression of D-type cyclins and overall survival (OS) and progression-free survival (PFS) of the DLBCL cases. The median survival time of the cohort of DLBCL patients was 39.1 months; $40.4 \%$ of patients survived 5 years. Cases exhibiting cyclin D2 expression demonstrated a trend toward worse OS and PFS, but this effect did not reach statistical significance $(\mathrm{P}=0.062$ and 0.134 , respectively). However, it reached clear statistical significance $(\mathrm{P}=0.016$ for $\mathrm{OS}$, and $\mathrm{P}=0.009$ for PFS) for DLBCL cases de novo (Fig. 6). Expression of cyclin D3 was not associated with OS $(\mathrm{P}=0.958)$ and PFS $(\mathrm{P}=0.822)$ (data not shown).

Association of cyclin D2 and D3 with de novo $C D 5^{+}$DLBCLs. The CD5 antigen expression was examined by immunohistochemistry. CD5 positivity was detected in 13 DLBCL cases (12.5\%) including 8 de novo cases. The CD5-positive cases demonstrated a trend toward worse OS, but this effect did not reach statistical significance $(\mathrm{P}=0.124)$. Cyclin $\mathrm{D} 2$ was overexpressed in $25 \%$ of de novo $\mathrm{CD}^{+}$DLBCLs $(2 / 8)$ and in $4.1 \%$ of de novo CD5- DLBCLs (3/73). A statistical analysis of this phenomenon was not performed because of the low number of cases in the $\mathrm{CD5}^{+}$arm of the study, although the higher expression of cyclin D2 appeared to be connected to the $\mathrm{CD}^{+}$ phenotype. The concurrent cyclin D3- and CD5-positivity was found in only one secondary case of DLBCL (D3) and it was not detected among the DLBCL cases de novo.

\section{Discussion}

In the present study, we performed expression analysis of cyclin D1, D2 and D3 in tumor samples from MCL and DLBCL cases using quantitative RT-PCR. This method is not performed as part of routine diagnostic procedures for MCL/DLBCL.

Cyclin D1 overexpression is a diagnostic marker of MCL and thus it is assessed routinely. Immunohistochemical analysis and/or fluorescence in situ hybridization (FISH) are almost exclusively employed techniques. It has been previously shown that assessment of cyclin D1 mRNA expression by qRT-PCR is helpful and is a specific tool for the diagnosis of MCL providing an alternative to FISH and immunohistochemistry (32-35). In the first part of our study, we confirmed this. The MCL cases with translocation $t(11 ; 14)$ and a high level of the cyclin D1 protein also showed a high level of cyclin D1 mRNA. Second, the cyclin D1-positive MCL cases exhibited significant overexpression of cyclin D1 mRNA ranging from a 5- to 75-fold increase over the values found in the nonneoplastic specimens, thus reliably distinguishing cyclin D1 positivity from negativity. This was clearly documented also by analysis of the cyclin D1-negative MCL case M5 (27 case $25 \mathrm{~B}$ ) as reported previously, which scored substantially under the cut-off level (Fig. 1A). 

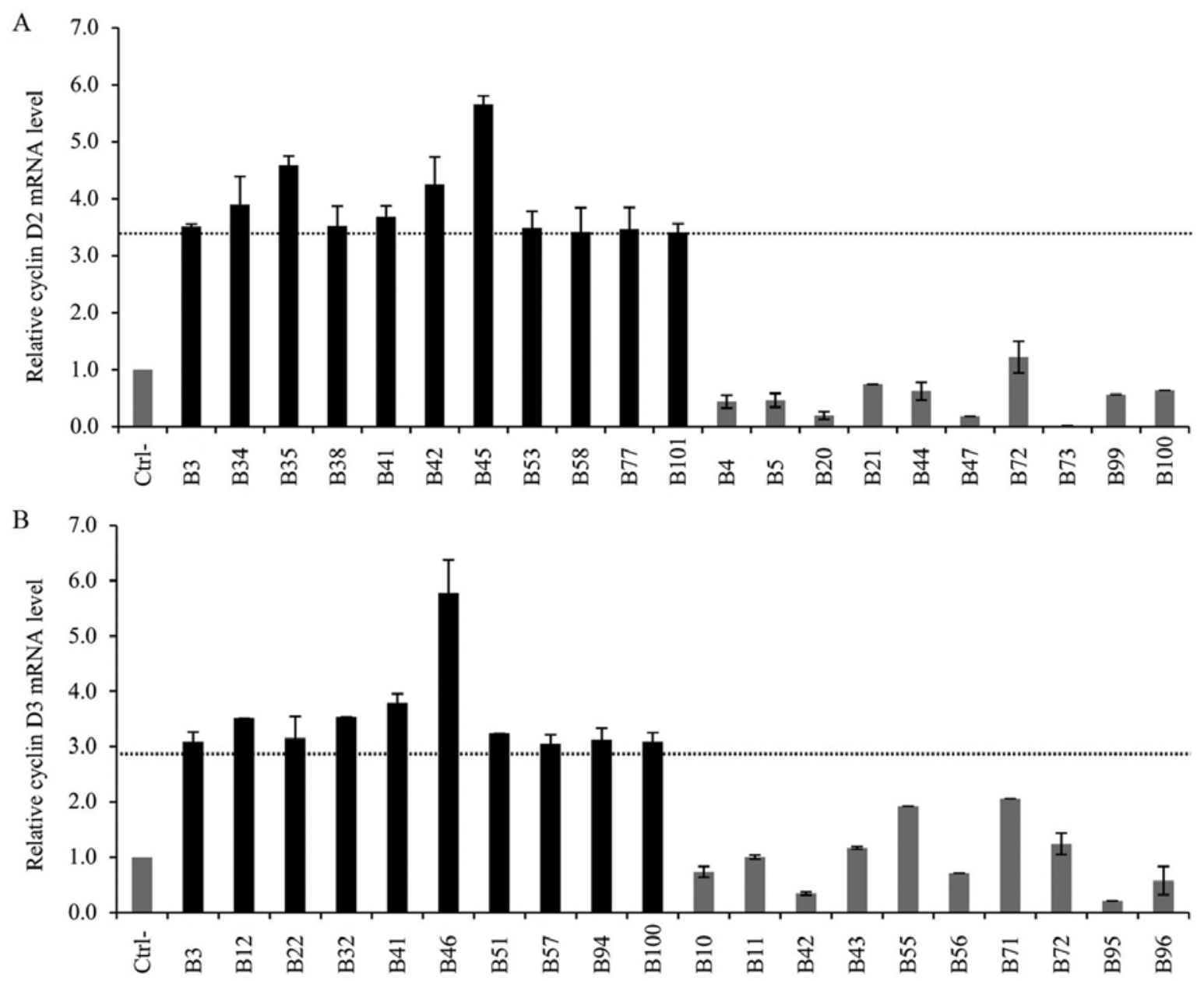

Figure 4. Analysis of the D type cyclins in representative DLBCL samples by qRT-PCR. Relative quantification of cyclin D2 (A) and cyclin D3 (B) expression in comparison to healthy donors (Ctrl-) is presented. Data are expressed as means $\pm \mathrm{SD}$.

\section{Ctrl+ B31 B32 B51 B46 B57 B59 B94 B100}

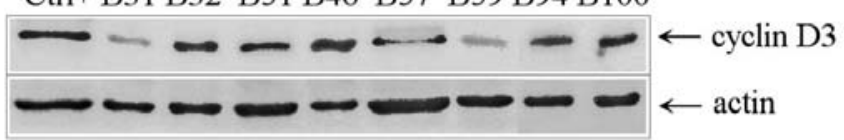

Figure 5. Analysis of the cyclin D3 protein in representative DLBCL cases by immunoblotting using Ab-1 monoclonal antibody. Jurkat cells served as a positive control (Ctrl+).

qRT-PCR is rapid, sensitive, specific, reproducible and thus a convenient technique for the routine analysis of gene expression. In comparison to other methods, it allows quantitative assessment of CCND1 mRNA. However, for diagnostic purposes, knowledge of the exact level of $C C N D I$ mRNA (or protein) is often dispensable. Simple qualitative 'positive-negative' resolution may be sufficient. In addition, according to our experience, RNA isolated from formalinfixed paraffin-embedded tumor tissue blocks is often degraded to such an extent that prevents reliable qRT-PCR analysis. From a practical point of view, the necessity to use fresh or deeply frozen tumor tissues may be limiting in some clinical institutions. Having the option to use formalin-fixed paraffinembedded tumor tissue blocks clearly shifts the preference to FISH and IHC.
The CCNDI mRNA below the cut-off limit was detected in MCL case M5 that was previously described as cyclin D1-negative/cyclin D2-positive. In the previous report, cyclin D2 positivity was assessed by immunoblotting using the cyclin D2-specific antibody Ab-4 (27 - case 25B). In the present study, the level of cyclin D2 mRNA was analyzed by qRT-PCR. In this particular case, the analyses detected a high level of cyclin D2 mRNA indeed, thus confirming the earlier conclusion. Interestingly, one of the cyclin D1-positive MCL cases, M2, scored also positive for CCND2 mRNA by qRT-PCR analysis. Although we failed to detect the cyclin D2 protein in this case, the $C C N D 1 / C C N D 2$ mRNA values were rather balanced as determined by competitive RT-PCR analysis (27 - case 27). On the other hand, a few more cases scored comparably balanced in CCND1/CCND2 mRNAs by competitive RT-PCR (27 - cases 30 and 32); none of them scored positive by the qRT-PCR analysis of $C C N D 2$ mRNA (cases M6 and M7).

Expression of CCND3 above the cut-off limit was observed in $6 \mathrm{MCL}$ cases, including case M2 which scored positive for all three types of cyclin D, and M5 with concurrent high expression of cyclin D2. The competitive RT-PCR analysis showed that the level of cyclin D3 was generally very low compared to cyclin D1 and/or D2 (27). This suggests that 
A

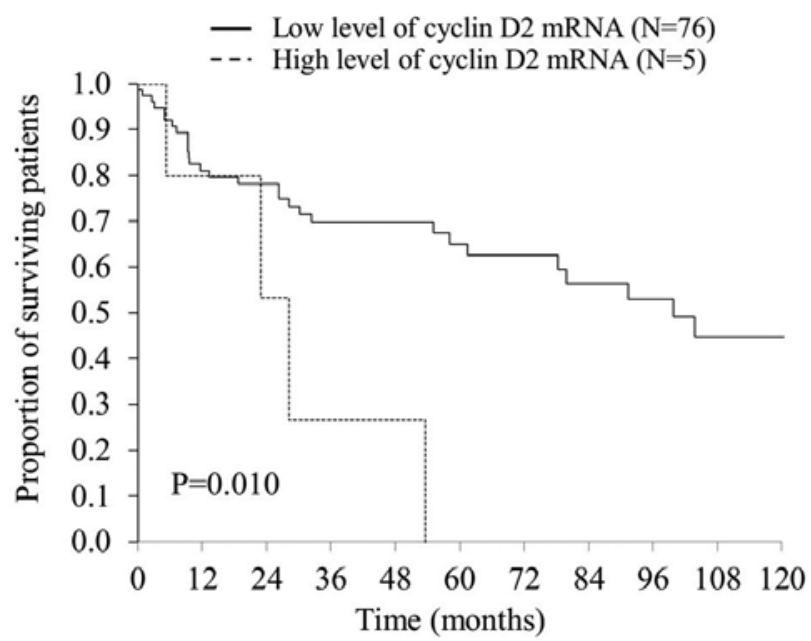

B

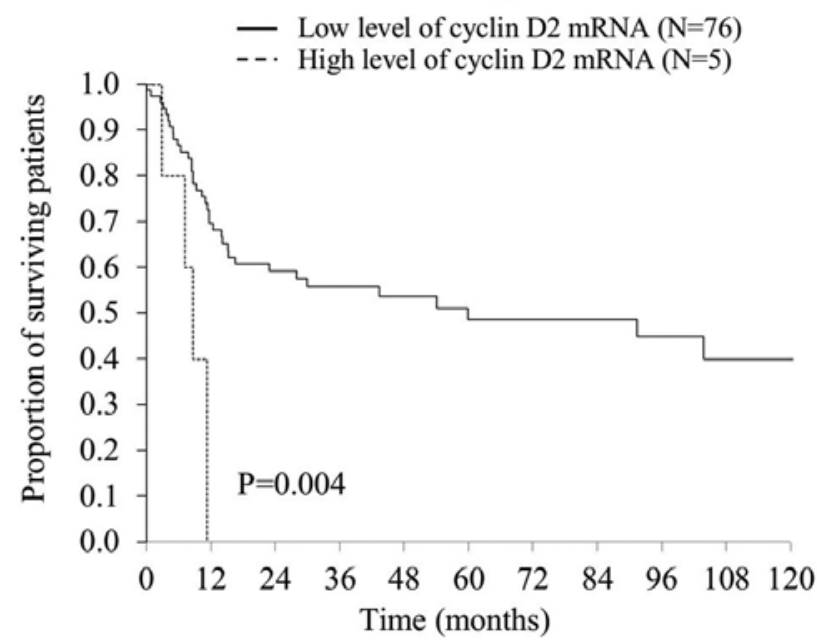

Figure 6. Overall survival (OS) (A) and progression-free survival (PFS) (B) of the de novo DLBCL patients based on high and low expression of cyclin D2 mRNA.

although the $6 \mathrm{MCL}$ cases exhibited a significantly elevated level of cyclin D3 mRNA relative to the non-neoplastic specimen, the real level may be very low.

Nevertheless, although the low incidence of cyclin D1negative and cyclin D2- or D3-positive MCL cases has been confirmed (5), the presence of cyclin D2 or D3 is not specific for MCL and cannot be used as a criterion for reliable diagnosis of this disease. For example, Quintanilla-Martinez et al (36) found cyclin D2 in most B-cell non-Hodgkin lymphomas using immunohistochemistry. Cyclin D3 was also found in non-Hodgkin and classical Hodgkin lymphomas $(18,37,38)$. In the present study, we confirmed that expression of cyclin D2 and D3 is not MCL-specific as we found several positive cases among the DLBCL patients.

In contrast to several studies $(15-18,20,21)$ we did not detect any cyclin D1-positive case in the cohort of 104 DLBCL patients. Apart from case reports, the incidence of cyclin D1 positivity among DLBCL cases described by others ranges from 1.5 to $4.3 \%$ with the exception of Vela-Chávez et al study (20) indicating $15 \%$. The referred studies usually employed immunohistochemical detection of the cyclin D1 protein, while we performed quantitative assessment of CCND1 mRNA. This may be an explanation of the difference. In addition, the possibility of misdiagnosed positive DLBCL cases is not excluded as Ok et al (39) recently identified 6 tumors originally classified as cyclin D1-positive DLBCL and reclassified them later as likely pleomorphic MCL. Other authors also considered such misdiagnosed cases $(15,21)$. Recently, a report of two blastoid B-cell lymphoma, most probably DLBCL cases, displaying the CCND1 gene rearrangement and high cyclin D1 expression suggests the existence of a diagnostic 'gray zone' between DLBCL and MCL (40). On the other hand, with respect to the size of our cohort (104 patients) and suggested the low prevalence of cyclin D1 positivity (1.5-4.3\%) we cannot reliably exclude the rare occurrence of the cyclin D1-positive DLBCL case. Nevertheless, our results rather support the former idea of DLBCL cases as cyclin D1-negative or at least the very rare occurrence of cyclin D1 positivity among DLBCL cases $(26,41)$.
The frequency of cyclin D2 positivity in DLBCL was found to vary between 13 and $62 \%$ in previous studies and it has been suggested as an adverse marker of DLBCL $(12,18,22,23,28,42)$. The analyses were performed either immunohistochemically or by qRT-PCR. In our study, overexpressed CCND2 mRNA was found in 11 DLBCL cases (10.6\%). Cyclin D2 expression was negatively related with overall survival but this effect was not statistically significant $(\mathrm{P}=0.062)$. However, when analyzing de novo and secondary DLBCL cases separately, we found that the cyclin D2 positivity, although much less frequent among the de novo cases [5/81 (6.2\%)], represents a clear adverse marker. This result is in agreement with previous studies $(13,22,28)$.

Overexpression of cyclin D2 was also found to be associated with CD5 positivity in DLBCL, especially in de novo cases (24). In our cohort, the low number of cyclin D2-positive cases also did not allow statistical analysis. Nevertheless, the tendency was rather clear. Cyclin D2 was overexpressed in 2 of 8 CD5-positive cases, while only in 3 of 73 CD5-negative cases.

The expression of cyclin D3 in DLBCL has been also studied by various groups and again with rather inconsistent results. The positivity assessed by immunohistochemistry scored between 20 and 62\% $(18,22,26)$. While Filipits et al (26) demonstrated that high expression of cyclin D3 in tumors (detected in $38 \%$ cases) is associated with a significantly lower complete remission rate and shorter 3-year overall survival, Hans et al (22), detecting cyclin D3 overexpression in $62 \%$ of cases, found no effect on survival. In our cohort, cyclin D3 mRNA positivity occurred in 9.6\% DLBCL cases and we did not find any impact on overall survival $(\mathrm{P}=0.958)$. Part of the explanation, similarly to MCL cases, may be the actual level of cyclin D3 mRNA which seems to be substantially lower in comparison to cyclin D1 and D2 as indicated by competitive RT-PCR (27).

In conclusion, we used qRT-PCR to study the expression of cyclin D1, D2 and D3 in MCL and DLBCL cases. We showed that the cyclin D1 expression was limited to MCL and did not 
occur in DLBCL cases. Overexpression of cyclin D2, rare in MCL, occured in a distinct portion of the DLBCL cases and may serve as a negative prognostic marker. Expression of cyclin D3 was found in comparable frequency in both types of studied lymphomas but did not display any statistically significant effect on disease outcome.

\section{Acknowledgements}

We thank Eva Bartova and Ales Hampl/Dasa Dolezalova for providing us with the MOLP-8 and Jurkat cells. This study was supported by grant NT/13784-4/2012 of the Internal Grant Agency of the Ministry of Health of the Czech Republic, and by MH CZ - DRO (FNBr, 65269705).

\section{References}

1. Sherr CJ: D-type cyclins. Trends Biochem Sci 20: 187-190, 1995.

2. Musgrove EA, Caldon CE, Barraclough J, Stone A and Sutherland RL: Cyclin D as a therapeutic target in cancer. Nat Rev Cancer 11: 558-572, 2011.

3. Banks PM, Chan J, Cleary ML, Delsol G, De Wolf-Peeters C, Gatter K, Grogan TM, Harris NL, Isaacson PG, Jaffe ES et al: Mantle cell lymphoma. A proposal for unification of morphologic, immunologic, and molecular data. Am J Surg Pathol 16: 637-640, 1992.

4. Bartkova J, Lukas J, Strauss M and Bartek J: Cell cycle-related variation and tissue-restricted expression of human cyclin D1 protein. J Pathol 172: 237-245, 1994.

5. Salaverria I, Royo C, Carvajal-Cuenca A, Clot G, Navarro A, Valera A, Song JY, Woroniecka R, Rymkiewicz G, Klapper W, et al: CCND2 rearrangements are the most frequent genetic events in cyclin D1(-) mantle cell lymphoma. Blood 121: 1394-1402, 2013.

6. Swerdlow SH, Campo E, Harris NL, Jaffe ES, Pileri SA, Stein H, Thiele $\mathbf{J}$ and Vardiman JW: WHO Classification of Tumours of Hematopoietic and Lymphoid Tissues. 4th edition. IARC, Lyon, France, 2008.

7. Ye BH, Rao PH, Chaganti RS and Dalla-Favera R: Cloning of bcl-6, the locus involved in chromosome translocations affecting band 3q27 in B-cell lymphoma. Cancer Res 53: 2732-2735, 1993.

8. Gascoyne RD, Adomat SA, Krajewski S, Krajewska M, Horsman DE, Tolcher AW, O'Reilly SE, Hoskins P, Coldman AJ, Reed JC, et al: Prognostic significance of $\mathrm{Bcl}-2$ protein expression and $\mathrm{Bcl}-2$ gene rearrangement in diffuse aggressive non-Hodgkin's lymphoma. Blood 90: 244-251, 1997.

9. Savage KJ, Johnson NA, Ben-Neriah S, Connors JM, Sehn LH, Farinha P, Horsman DE and Gascoyne RD: MYC gene rearrangements are associated with a poor prognosis in diffuse large B-cell lymphoma patients treated with R-CHOP chemotherapy. Blood 114: 3533-3537, 2009.

10. Barrans S, Crouch S, Smith A, Turner K, Owen R, Patmore R, Roman E and Jack A: Rearrangement of MYC is associated with poor prognosis in patients with diffuse large B-cell lymphoma treated in the era of rituximab. J Clin Oncol 28: 3360-3365, 2010.

11. Xu-Monette ZY, Wu L, Visco C, Tai YC, Tzankov A, Liu WM, Montes-Moreno S, Dybkaer K, Chiu A, Orazi A, et al: Mutational profile and prognostic significance of TP53 in diffuse large B-cell lymphoma patients treated with R-CHOP: Report from an International DLBCL Rituximab-CHOP Consortium Program Study. Blood 120: 3986-3996, 2012.

12. Alizadeh AA, Eisen MB, Davis RE, Ma C, Lossos IS, Rosenwald A, Boldrick JC, Sabet H, Tran T, Yu X, et al: Distinct types of diffuse large B-cell lymphoma identified by gene expression profiling. Nature 403: 503-511, 2000.

13. Lossos IS, Czerwinski DK, Alizadeh AA, Wechser MA, Tibshirani R, Botstein D and Levy R: Prediction of survival in diffuse large-B-cell lymphoma based on the expression of six genes. N Engl J Med 350: 1828-1837, 2004.

14. Horn H, Ziepert M, Becher C, Barth TF, Bernd HW, Feller AC, Klapper W, Hummel M, Stein H, Hansmann ML, et al; German High-Grade Non-Hodgkin Lymphoma Study Group: MYC status in concert with BCL2 and BCL6 expression predicts outcome in diffuse large B-cell lymphoma. Blood 121: 2253-2263, 2013.
15. Ehinger M, Linderoth J, Christensson B, Sander B and Cavallin-Ståhl E: A subset of CD5- diffuse large B-cell lymphomas expresses nuclear cyclin D1 with aberrations at the CCND1 locus. Am J Clin Pathol 129: 630-638, 2008.

16. Rodriguez-Justo M, Huang Y, Ye H, Liu H, Chuang SS, Munson P, Prada-Puentes C, Kim I, Du MQ and Bacon CM: Cyclin D1-positive diffuse large B-cell lymphoma. Histopathology 52: 900-903, 2008

17. Teruya-Feldstein J, Gopalan A and Moskowitz CH: CD5 negative, cyclin D1-positive diffuse large B-cell lymphoma (DLBCL) presenting as ruptured spleen. Appl Immunohistochem Mol Morphol 17: 255-258, 2009.

18. Metcalf RA, Zhao S, Anderson MW, Lu ZS, Galperin I, Marinelli RJ, Cherry AM, Lossos IS and Natkunam Y: Characterization of D-cyclin proteins in hematolymphoid neoplasms: Lack of specificity of cyclin-D2 and D3 expression in lymphoma subtypes. Mod Pathol 23: 420-433, 2010.

19. Lucioni M, Novara F, Riboni R, Fiandrino G, Nicola M, Kindl S, Boveri E, Jemos V, Arcaini L, Zuffardi O, et al: CD5(-) diffuse large B-cell lymphoma with peculiar cyclin $\mathrm{D} 1^{+}$phenotype. Pathologic and molecular characterization of a single case. Hum Pathol 42: 1204-1208, 2011.

20. Vela-Chávez T, Adam P, Kremer M,Bink K, Bacon CM, Menon G, Ferry JA, Fend F, Jaffe ES and Quintanilla-Martínez L: Cyclin D1 positive diffuse large B-cell lymphoma is a post-germinal center-type lymphoma without alterations in the CCND1 gene locus. Leuk Lymphoma 52: 458-466, 2011.

21. Hsiao SC, Cortada IR, Colomo L, Ye H, Liu H, Kuo SY, Lin SH, Chang ST, Kuo TU, Campo E, et al: SOX11 is useful in differentiating cyclin D1-positive diffuse large B-cell lymphoma from mantle cell lymphoma. Histopathology 61: 685-693, 2012.

22. Hans CP, Weisenburger DD, Greiner TC, Chan WC, Aoun P, Cochran GT, Pan Z, Smith LM, Lynch JC, Bociek RG, et al: Expression of PKC-beta or cyclin D2 predicts for inferior survival in diffuse large B-cell lymphoma. Mod Pathol 18: $1377-1384,2005$

23. Amen F, Horncastle D, Elderfield K, Banham AH, Bower M, Macdonald D, Kanfer E and Naresh KN: Absence of cyclin-D2 and Bcl-2 expression within the germinal centre type of diffuse large B-cell lymphoma identifies a very good prognostic subgroup of patients. Histopathology 51: 70-79, 2007.

24. Igawa T, Sato Y, Takata K, Iwaki N, Tanaka T, Asano N, Maeda Y, Orita Y, Nakamura N, Nakamura S, et al: De novo CD5-positive diffuse large B-cell lymphomas show high specificity for cyclin D2 expression. Diagn Pathol 8: 81, 2013.

25. Yamaguchi $M$, Seto $M$, Okamoto $M$, Ichinohasama $R$, Nakamura N, Yoshino T, Suzumiya J, Murase T, Miura I, Akasaka $\mathrm{T}$, et al: De novo $\mathrm{CD}^{+}$diffuse large B-cell lymphoma: A clinicopathologic study of 109 patients. Blood 99: 815-821, 2002.

26. Filipits M, Jaeger U, Pohl G, Stranzl T, Simonitsch I, Kaider A, Skrabs C and Pirker R: Cyclin D3 is a predictive and prognostic factor in diffuse large B-cell lymphoma. Clin Cancer Res 8: 729-733, 2002.

27. Stefancikova L, Moulis M, Fabian P, Falkova I, Vasova I, Kren L, Macak J and Smardova J: Complex analysis of cyclin D1 expression in mantle cell lymphoma: Two cyclin D1-negative cases detected. J Clin Pathol 62: 948-950, 2009.

28. Hans CP, Weisenburger DD, Greiner TC, Gascoyne RD, Delabie J, Ott G, Müller-Hermelink HK, Campo E, Braziel RM, Jaffe ES, et al: Confirmation of the molecular classification of diffuse large B-cell lymphoma by immunohistochemistry using a tissue microarray. Blood 103: 275-282, 2004.

29. Muris JJF, Meijer CJLM, Vos W, van Krieken JH, Jiwa NM, Ossenkoppele GJ and Oudejans JJ: Immunohistochemical profiling based on Bcl-2, CD10 and MUM1 expression improves risk stratification in patients with primary nodal diffuse large B cell lymphoma. J Pathol 208: 714-723, 2006.

30. Matsuo Y, Drexler HG, Harashima A, Okochi A, Hasegawa A, Kojima K and Orita K: Induction of CD28 on the new myeloma cell line MOLP-8 with $\mathrm{t}(11 ; 14)(\mathrm{q} 13 ; \mathrm{q} 32)$ expressing delta/lambda type immunoglobulin. Leuk Res 28: 869-877, 2004.

31. Szepesi A, Gelfand EW and Lucas JJ: Association of proliferating cell nuclear antigen with cyclin-dependent kinases and cyclins in normal and transformed human T lymphocytes. Blood 84: 3413-3421, 1994

32. Bijwaard KE, Aguilera NS, Monczak Y, Trudel M, Taubenberger JK and Lichy JH: Quantitative real-time reverse transcription-PCR assay for cyclin D1 expression: Utility in the diagnosis of mantle cell lymphoma. Clin Chem 47: 195-201, 2001. 
33. Hui P, Howe JG, Crouch J, Nimmakayalu M, Qumsiyeh MB, Tallini G, Flynn SD and Smith BR: Real-time quantitative RT-PCR of cyclin D1 mRNA in mantle cell lymphoma: Comparison with FISH and immunohistochemistry. Leuk Lymphoma 44: 1385-1394, 2003.

34. Brizova H, Kalinova M, Krskova L, Mrhalova M and Kodet R: Quantitative measurement of cyclin D1 mRNA, a potent diagnostic tool to separate mantle cell lymphoma from other B-cell lymphoproliferative disorders. Diagn Mol Pathol 17: 39-50, 2008.

35. Cao X, Fan L, Fang C, Zhu DX, Dong HJ, Wang DM, Wang YH, $\mathrm{Xu}$ W and Li JY: The expression of SOX11, cyclin D1, cyclin D2, and cyclin D3 in B-cell lymphocytic proliferative diseases. Med Oncol 29: 1190-1196, 2012.

36. Quintanilla-Martinez L, Slotta-Huspenina J, Koch I, Klier M, Hsi ED, de Leval L, Klapper W, Gesk S, Siebert R and Fend F: Differential diagnosis of cyclin $\mathrm{D}^{+}$mantle cell lymphoma based on fluorescence in situ hybridization and quantitative real-time-PCR. Haematologica 94: 1595-1598, 2009.

37. Teramoto N, Pokrovskaja K, Szekely L, Polack A, Yoshino T, Akagi $\mathrm{T}$ and Klein G: Expression of cyclin D2 and D3 in lymphoid lesions. Int J Cancer 81: 543-550, 1999.

38. Møller MB, Nielsen O and Pedersen NT: Cyclin D3 expression in non-Hodgkin lymphoma. Correlation with other cell cycle regulators and clinical features. Am J Clin Pathol 115: 404-412, 2001.
39. Ok CY, Xu-Monette ZY, Tzankov A, O'Malley DP Montes-Moreno S, Visco C, Møller MB, Dybkaer K, Orazi A, $\mathrm{Zu} \mathrm{Y,} \mathrm{et} \mathrm{al:} \mathrm{Prevalence} \mathrm{and} \mathrm{clinical} \mathrm{implications} \mathrm{of} \mathrm{cyclin} \mathrm{D1}$ expression in diffuse large B-cell lymphoma (DLBCL) treated with immunochemotherapy: A report from the International DLBCL Rituximab-CHOP Consortium Program. Cancer 120: 1818-1829, 2014.

40. Juskevicius D, Ruiz C, Dirnhofer S and Tzankov A: Clinical, morphologic, phenotypic, and genetic evidence of cyclin D1-positive diffuse large B-cell lymphomas with CYCLIN D1 gene rearrangements. Am J Surg Pathol 38: 719-727, 2014.

41. Bai M, Tsanou E, Agnantis NJ, Chaidos A, Dimou D, Skyrlas A, Dimou S, Vlychou M, Galani V and Kanavaros P: Expression of cyclin D3 and cyclin E and identification of distinct clusters of proliferation and apoptosis in diffuse large B-cell lymphomas. Histol Histopathol 18: 449-457, 2003.

42. Malumbres R, Chen J, Tibshirani R, Johnson NA, Sehn LH, Natkunam Y, Briones J, Advani R, Connors JM, Byrne GE, et al: Paraffin-based 6-gene model predicts outcome in diffuse large B-cell lymphoma patients treated with R-CHOP. Blood 111: 5509-5514, 2008 . 